\title{
Analysis of Visual and Verbal Rhetorical Strategies in Advertising Discourse From Cognitive Perspective
}

\section{Reham Sayed Sedeeq*}

\section{Rehamsayed141@gmail}

\section{Abstract}

Pictorial metaphor is a form of rhetorical tropes depicted in images that have a powerful persuasion in advertising. The visual devices in advertising are considered to be an essential, interrelated, meaningful, and culturally embodied characteristic of contemporary advertising. A visual metaphor is used frequently in advertisements by depicting one domain of experience (target domain) in terms of another domain of experience (source domain). With regards to academic research, the emphasis was laid on initially verbal metaphor. The current research sets out to measure the impact of two different metaphor types namely; verbo-pictorial metaphor and replacement metaphor within an advertising context on consumer response. A group of 80 professors from three Egyptian universities participated in this experiment.The Results related to the objective metaphor comprehension indicate the importance of the functional characteristics as a key element that participants focus on when solving the visual metaphors. Results from this experiment

\footnotetext{
* Assistant Lecturer - English Department - Faculty of Arts.
}

(Analysis of Visual and Verbal Rhetorical Strategies...) Reham Sayed 
showed that replacement metaphor had the most positive effect on comprehension of the advertisement.

Keywords: Visual metaphor, target domain, source domain, replacement metaphor, verbo-pictorial metaphor, comprehension, advertisement.

\section{Introduction}

With the drastic changes recently brought about into the field of advertising by the stunning technological advances, researchers in the field are showing deeper interest in studying the impact of such inseparable part of our modern lifestyle from a variety of points of view. In the fields of marketing and advertising, language has an extraordinary power to shape and construct our perception and attitude towards a specific product. Goddard (2002) suggested that "although advertisements are ephemeral in that each one is short-lived; their effects are longstanding and cumulative" (p.3).

One of the most powerful instruments that advertising agencies has is not only verbal text, but also image. The modern trend of advertising eliminates verbal parts and increases a shift towards pictorial elements. Often the only textual part of the advertisement is the product name or the

(Analysis of Visual and Verbal Rhetorical Strategies...) Reham Sayed 
slogan. Research in the field of visual rhetoric in advertising suggests that the emphasis on pictorial elements over words has steadily increased throughout the last century (Phillips and McQuarrie, 2004).

\section{Significance of the Research}

Regarding its substance as an artful deviation from familiar expectation, consumers' reactions to advertisements that contain various types of pictorial metaphor is worth investigated. Although there is abundant research on pictorial metaphors, limited empirical research has been done to determine how consumers interpret and comprehend them. This research proposes to verify, through experimentation, the effect of different types of visual metaphor on (a) comprehension and (b) attitude toward the advertisement. The study will set out to assess not only the direct effect of visual metaphor, but also the moderating role of comprehension in altering consumer attitude toward the advertisement. Moreover, the study highlights how powerful the visual component is in advertising. Although there is abundance of literature on pictorial metaphor in advertisement, very little is known about how various types of visual metaphor elicit response from consumer.

(Analysis of Visual and Verbal Rhetorical Strategies...) Reham Sayed 
Depending upon Forceville's typology (1996), this research attempts to gain a better understanding of the main visual techniques that advertisers use to attract attention of their clients and make them choose their products or services by affecting their emotions.

\section{Hypotheses of the Research}

The visual devices in advertising are considered to be an essential, interrelated, meaningful, and culturally embodied characteristic of contemporary advertising (McQuarrie and Mick, 1999, p.51). Visual metaphor is one of the most commonly used rhetorical figures in advertising. Metaphor's strength lies in its ability to view characteristics by means of contrast or cross domain mapping. Given that pictorial metaphor is essentially a form of indirect persuasion, one might ask whether the various types of metaphors can be enjoyed and interpreted differently by the selected participants or not. This research hypothesized that

H1: The level of comprehension will increase gradually starting from replacement, moving through verbo-pictorial metaphor.

(Analysis of Visual and Verbal Rhetorical Strategies...) Reham Sayed 
H2: Comprehension will mediate the effect of visual metaphor on

H3: Attitude toward the ad will increase gradually starting from verbo-pictorial moving through replacement metaphor.

\section{Theoretical Framework}

To achieve the aim of this study the researcher applies Forceville's typology (1996) which distinguished two types of visual metaphors:

1) Replacement: this type presents only one image, either the primary subject or the secondary subject, while the intended picture is absent.

2) Verbo-pictorial: depends on a comparison between two objects where one of the terms is rendered visually and the other is depicted verbally.

\section{a. Comprehension}

The most brilliant and original advertising ideas will be wasted if they are not comprehended by the prospective customers. Fundamentally, visual metaphors represent artful deviations from expectations (McQuarrie and Mick, 1996) and rely on cross domain comparisons. What makes the

(Analysis of Visual and Verbal Rhetorical Strategies...) Reham Sayed 
interpretation of metaphorical meanings in product advertising more complex is the incongruity in visual metaphors. As a type of rhetorical figure, visual metaphors are likely to increase audiences' need for cognitive effort to fill in the gaps. To comprehend an advertising metaphor, the consumer need to recognize, understand and are capable of cracking a puzzle and drive inferences from visual metaphors in advertising. However viewers' comprehension of the ad is a central phase of consumer response, prior researches on metaphor comprehension are scattered (Ma, 2008; McQuarrie and Mick, 1999; Morgan and Reichert, 1999; van Mulken, Pair, and Forceville, 2010).

Since "consumers must interpret and transfer relevant properties from one image to another while ignoring irrelevant similarities" (Phillips, 2000, p.78). Scholars and practitioners in consumer researches noted that metaphors in ads are not always comprehended as their creators intended (Phillips, 1997). Accordingly, consumers infer more than one meaning when encountering ads containing visual metaphors. In her study, she found that consumers interpreted an ad's message by deciding among the various strong and weak implicatures from images in the ads

(Analysis of Visual and Verbal Rhetorical Strategies...) Reham Sayed 
(Phillips, 1997). Strong implicatures refer to the intended meaning of the ad. When the consumer lost the advertiser's main meaning for the ad, he creates weak implicatures. Such weak implicatures are based on consumer's idiosyncratic readings of the visual metaphor (Phillip, 1997).

Mick's (1992) widely cited article distinguishes between subjective and objective comprehension. According to him, subjective comprehension refers to "the generation of meanings by a particular individual through the activation of mental concepts related to the message and the processing context" (Mick, 1992, p.412). In the context of this research, the subjective orientation toward message comprehension refers to the consumers' personal perception regarding the extent they believe they have understood the ad or they did not grasp the meaning. On the other hand, objective comprehension is defined as "the grasping or extracting of pre-specifiable meanings from the message" (Mick, 1992, p. 411). Under this objective orientation, the message comprehension is authentic to the intention of the advertiser and depending necessarily upon message-based meanings.

(Analysis of Visual and Verbal Rhetorical Strategies...) Reham Sayed 


\section{b. Attitude towards the Advertisement}

Visual metaphors are ambiguous puzzles since they urge the viewer to exert mental effort to comprehend how one thing resembles or is linked to another (Van Mulken, Hooft and Nederstigt, 2014). The "artful deviation" in metaphors requires more cognitive effort from the consumer which in turn helps increasing message elaboration (McQuarrie \& Mick, 1996). Consumers' attitude toward the ad can be described as "a predisposition to respond in a favorable or unfavorable manner to a particular advertising stimulus during a particular exposure occasion" (Lutz, 1985, p.46). The following hypotheses are put forward relating to the impact of the two different types of visual metaphor on attitude toward the ad:

\section{Method}

\subsection{Data Collection}

The data of the present study is extracted from different websites. Twelve visual static advertisements on food and beverage were downloaded from

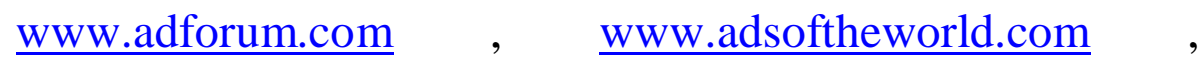
$\underline{\text { www.ateriet.com }}$ and www.pinterest.com. It is a

(Analysis of Visual and Verbal Rhetorical Strategies...) Reham Sayed 
representative enough sample to allow a through and weighty cognitive analysis of the verbal and pictorial features of each advertisement. Following Thorson (1990), the selected visual advertisements were chosen from authentic commercial advertisements that appeared in websites to increase the external validity and look appealing for participants in the research.

\section{Measures}

A set of items was used to measure the response of the participants after they had seen a stimulus.

\subsubsection{Independent Variables}

The independent variables are represented in the two types of visual metaphor, which are: replacement metaphor and verbo-pictorial metaphor.

\subsubsection{Mediating Variables}

Mediating Variables are the mechanisms through the researcher can understand how the independent variable is affecting the dependent variable and what is governing that relationship. In the current study, the mediating variables are

Advertisement Comprehension

(Analysis of Visual and Verbal Rhetorical Strategies...) Reham Sayed 


\subsubsection{Dependent Variables}

Attitude toward the ad can be described as "a predisposition to respond in a favorable or unfavorable manner to a particular advertising stimulus during a particular exposure occasion” (Lutz, 1985, p.46).

\subsection{Participants}

After the ad materials were decided, a survey measuring the ad likeability and understandability to pictorial metaphor in advertising was ready to be conducted. The test consisted of an online questionnaire, created in Google forum, displaying the selected (6) advertisements. Sample of (80) participants from English department staff in different universities took part in the survey.

\subsection{Qualitative Analysis}

This section comprises an analysis of the six advertisements under investigation using Forceville's typology (1996) and Incongruities models.

\section{(1) First set of advertisement: Replacement Metaphor}

This type of metaphor is elaborated through a set of three food and beverage advertisements that have the same

(Analysis of Visual and Verbal Rhetorical Strategies...) Reham Sayed 
structural features in common in order to convey the commercial intended message and achieve a positive effect on consumer response. All of the following three advertisements utilize the replacement metaphor which often combines a verbal phrase with a visual image to dramatize the required effect. Each advertisements displays a different form of replacement structures; either

I. a sole replacement with no context (Figure1 and 3) or

II. a replacement accompanied by a discourse from the target domain (Figure2)

\section{Ad No. 1}

1) Product name: Heinz

- $\quad$ Type of product: ketchup

- $\quad$ Text inside the image: Heinz tomato ketchup.

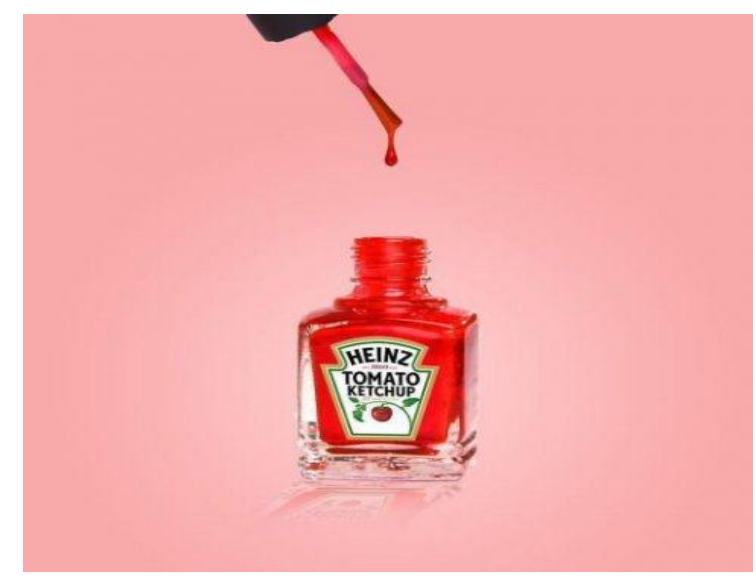

Figure (1)

(Analysis of Visual and Verbal Rhetorical Strategies...) Reham Sayed 
Figure (1) is an advertisement of ketchup where the desired message is to create a mental and conceptual image at the consumer that this ketchup is as luscious and succulent in color and attraction as beautifully designed nail paint. The image portrayed at this advertisement apparently complies the features of a replacement metaphor, where the target is replaced by the source. The replacement of the source (Heinz ketchup) with the target (the red nail paint) shows that they both have in common one perceptual property: color, which triggers the associative relation between them. The image of nail paint with the words 'Heinz-tomato-ketchup' provokes an analogy between the paint and the advertised product.

In the "ketchup" metaphorical advertisement, the ad producer provides limited verbal anchoring and the target audience has to work harder to decrypt the intended interpretation. With "Heinz" advertisement, the aim is to capture the attention of their consumers and spark the reader's interest depending on verbal and nonverbal elements using moderate amount of verbal anchoring (i.e., a headline that gives a clue to the desired message) without mentioning any common attributes between the two

(Analysis of Visual and Verbal Rhetorical Strategies...) Reham Sayed 
metaphorical terms rather than the product name. To add a touch of suspense and to ignite the receiver's appeal and interest in an advertisement, the designers always avoid providing any detailed explanation of the image, so the advertisement looks like a call to conceptually figure out the relationship between the advertisement elements.

Incongruent pictures have the effect of attracting people's attention, and when the perceivers look at incongruent pictures, they immediately try to solve them (Schilperoord, 2016). The bottle of nail paint in our advertisement represents the base entity (Establisher) which is the familiar entity. According to the One-model visual incongruities, the above image exemplifies distort. The distortion operation includes a range of operations which produce visual incongruities. Distort has several sub types that can produce a visual incongruity, these sub types are detach, support, change the shape, relocate the place, and enlarge/reduce the size. The above picture expresses this message by having the word Heinz on a bottle of polish.

(Analysis of Visual and Verbal Rhetorical Strategies...) Reham Sayed 


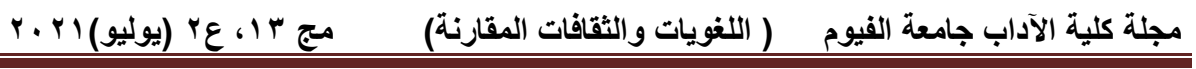

\section{Ad No.2}

1) Product name: Pepsi

- $\quad$ Type of product: soda beverage

- $\quad$ Text inside the image: come to life.

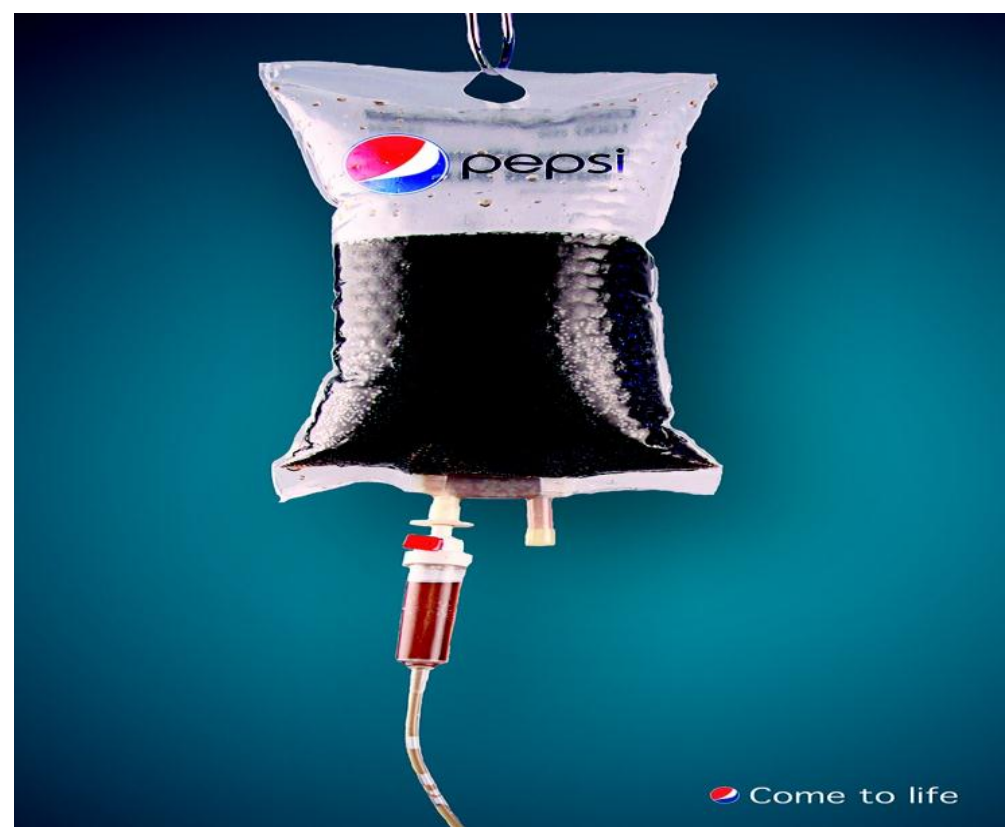

Figure (2)

The advertised product in this advertisement is Pepsi. The designer metaphorizes Pepsi as a source of life that is as important for life as blood for human beings. In prior studies, replacement structure seems to appear in various designs. In this advertisement, replacement metaphor is

(Analysis of Visual and Verbal Rhetorical Strategies...) Reham Sayed 
accompanied by context from the target domain. The perceptual similarity alongside with the contextual embedding of the Pepsi and blood is the starting point to establish a conceptual link between the two compared objects in order to elevate the conceptual and cognitive effectiveness of the advertisement. With the first look at the advertisement above; we may not perceive that this image implies a metaphor. Thanks to the pictorial context through which the viewer can conceptualize which is the absent term of the metaphor.

With that said, the verbal elements play a significant role in interpreting the intended commercial message. The cross-mapping domain encourages the reader to map relevant attributes from the source to the target (i.e. Pepsi is necessary in the same way blood is) which are reinforced and supported in the copy: "come to life". The blood bag also grabs the viewers' attention to the logo "Pepsi" the thing that helps to form a long-lasting mental image and a link to the advertised product.

Certain operations have been carried out on the base entity in Figure2; the advertised beverage substitutes blood. In doing so, deviations of the blood image's formal

(Analysis of Visual and Verbal Rhetorical Strategies...) Reham Sayed 
properties are created while allowing for immediate recognition of the iconic original photograph. Meanwhile, these deviations contribute to the VOI's overall meaning construction by involving a new level of conceptual meaning while maintaining its base entity's salient meaning. The replacement of the blood with the Pepsi represents the importance and pleasure posed by the soda beverage. The combination of the image with the accompanying text presents an analogical relationship and implies mappings between the necessity of blood and Pepsi. Such analogy supported by the slogan "come to life", which appears to be relevant to both of the domains represented visually.

\section{Ad No.3}

1) Product name: McDonald's

- $\quad$ Type of product: Sandwich

- $\quad$ Text inside the image:

(Analysis of Visual and Verbal Rhetorical Strategies...) Reham Sayed 


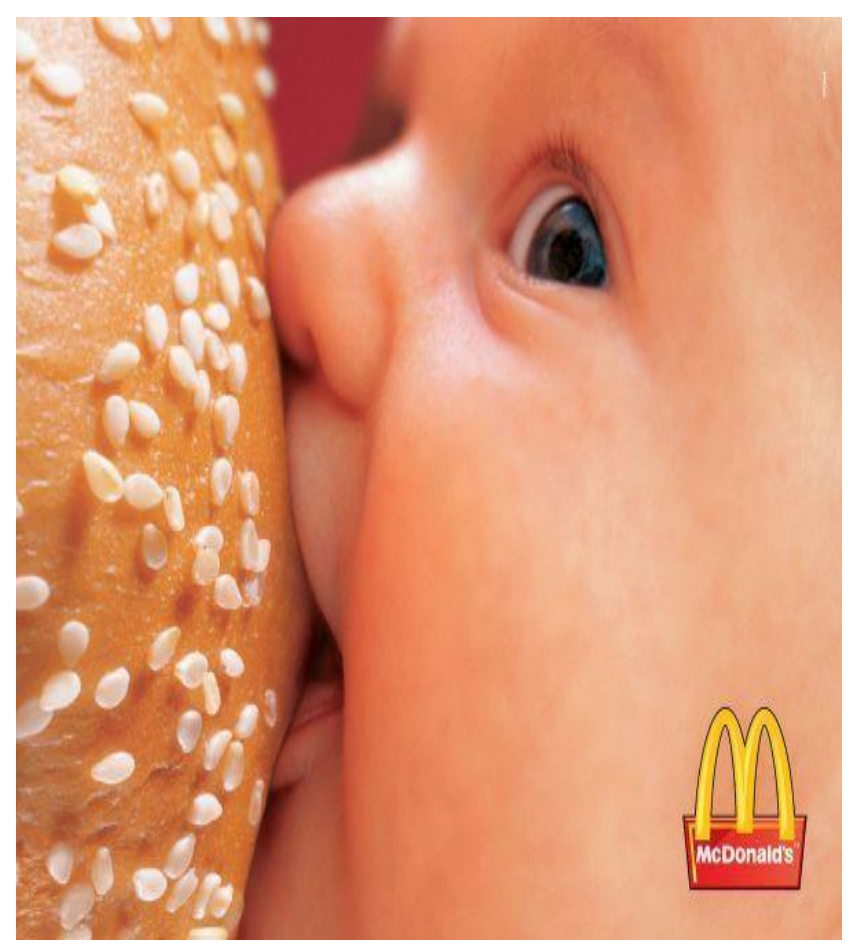

Figure (3)

The advertised product here is a sandwich. The background picture shows a baby nursing on mother's milk, but the motherly milk source here is a luscious McDonald's sandwich full of sesame seeds. The structured metaphor in this advertisement is a sole replacement. It is because the McDonald's sandwich substitutes the natural source of a mother's milk without any explaining text (except from the brand name). In other words, the viewer is tempted to understand the sandwich from a completely new perspective

(Analysis of Visual and Verbal Rhetorical Strategies...) Reham Sayed 
related to all the appeal and nutrients of a nursing mother's milk. The mapping of the source domain to the target domain connotes the meaning that Mac sandwich is healthy and useful for young children as their mother's milk. The metaphorical image connotes the idea that Mac is nutritive that can promote one's health and physical well-being; therefore, eating a Mac feels like being nursed, fostered and nurtured in the same way baby is.

As for the linguistic message in the advertisement, the verbal element is very few in this advertisement. The ad logo: "MacDonald's" functions as the only verbal context for the background picture. The viewer finds almost no clues but of the famous brand MacDonald's to indicate that this sandwich is one of their products. It is necessary to mention that prior cognitive studies have shown that for tropes to evoke favorable feelings and attitude they need to be comprehended by its target viewers. The advertisement likeability and appreciation may be reduced with complete verbal anchoring and at the same time additional verbal clues will be needed to analyze such replacement advertisements.

(Analysis of Visual and Verbal Rhetorical Strategies...) Reham Sayed 
From an incongruity perspective, the comprehension of the pictorial advertisements is almost instantaneous, while the resolution of incongruity requires finding the cross-mappings between the two juxtaposed entities and the reasoning for such an uncanny comparison. In the advertisement above, a hamburger replaces a feeding mother's breast, whereby a conspicuous incongruity occurs. The incongruity of the above ad is constructed by applying a particular assembling operation; that is substitute. As a subtype of the two-model incongruities, Entity $\mathrm{V}$ from the second cognitive model, substitutes an entity from the base cognitive model E. In Figure 3, a sandwich (V) that substitutes a nursing mother's breast (E model). The incongruous resides in the fact that mother's breast is metaphorically substituted with a sandwich or a product from the advertising brand. In order to interpret a visual incongruent picture, the viewer must find the projection of relevant qualities of the absent element onto the present one.

(Analysis of Visual and Verbal Rhetorical Strategies...) Reham Sayed 


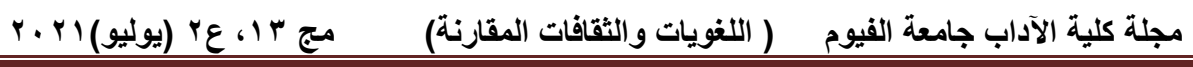

(2) Second Set of Advertisements: Verbo-pictorial

Metaphor

Ad No. 1

1) Product name: McDonald's

- $\quad$ Type of product: Sandwich

- $\quad$ Text inside the image: Fall is here

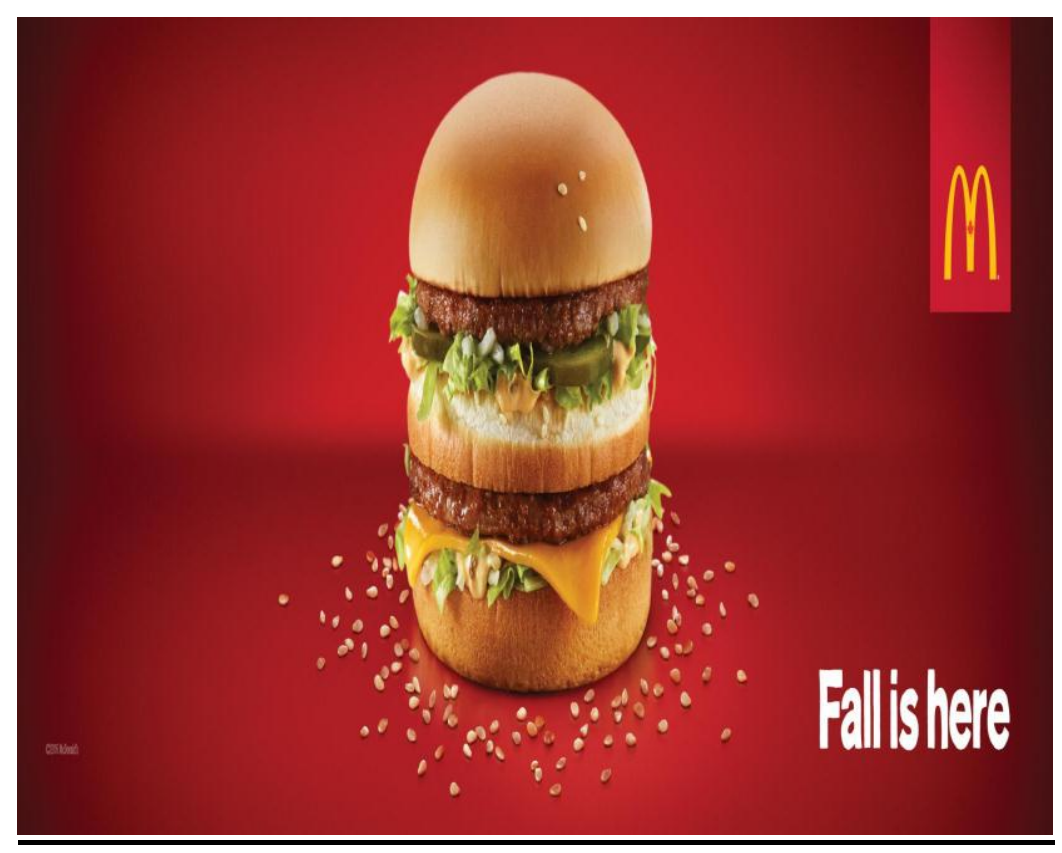

Figure (4)

The designer in this advertisement depends on visual and verbal metaphor in order to influence the consumer and gets their attention. Unlike the images previously discussed,

(Analysis of Visual and Verbal Rhetorical Strategies...) Reham Sayed 
the image here heavily depends on the text. Apparently, there is no connection between the visual image and the textual context. However, the surface similarity shows: Mac sandwich loses its sesame like a tree in the fall. To accomplish a comparative perspective in this advertisement, the designer has allegorized the sandwich as if it is a tree shedding leaves in the fall. In a pictorial level, we can presume that sesame is a very important ingredient of the sandwich. The idea is also fulfilled by the hint to the fall. Through the verbal text 'fall is here', another possible interpretation of the advertisement can be "Fall is the season to dine in". If not for the text ('fall is here' and the logo 'Mac'), questioning about the sandwich losing its sesame, it would be very complicated to tell what product is being advertised.

The pictorial element is not enough to grasp the contextual information as the verbal element establishes the connection between source and target. The verbal anchoring makes the metaphor easy to decrypt. This advertisement proves the intersecting relation between the verbal and textual elements in comprehending the verbo-pictorial metaphor. The textual elements perform a double function:

(Analysis of Visual and Verbal Rhetorical Strategies...) Reham Sayed 
it enhances the product features and helps to decode the visual metaphor, thus working as an advertising strategy. The advertisement always achieves its goal through the mastery in providing both components in a harmonized way that serves the message rather than missing one of them or missing the expected contextual relationship among these components.

\section{Ad No.2}

1) Product name: Nescafe

- $\quad$ Type of product: Nescafe

- $\quad$ Text inside the image: wake up to life

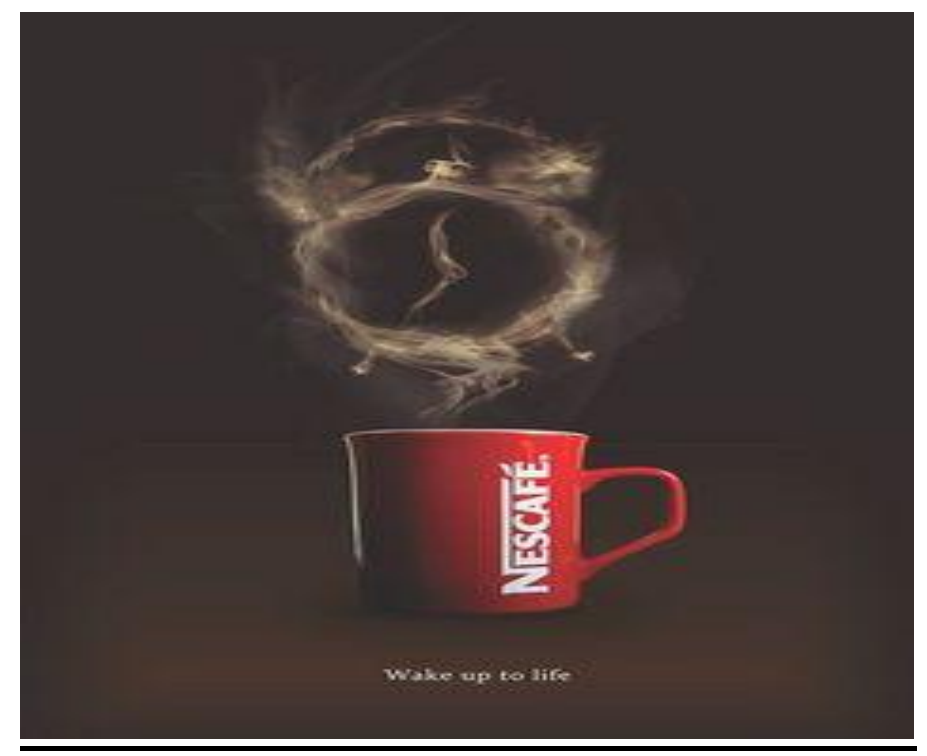

Figure (5)

(Analysis of Visual and Verbal Rhetorical Strategies...) Reham Sayed 
Metaphors depend on associating certain elements from the source domain with elements from the target domain. Producers of advertisements convey their ideas via two separate but complementary messages; a linguistic message and a pictorial message. In the above advertisement, the source domain (alarm) is presented pictorially and the target domain (Nescafe) is presented verbally. In figure (5), the producer wants to indicate how necessary Nescafe is and that the consumer is supposed to feel the liveliness when consuming it. Therefore, the advertiser uses the shape of alarm particularly because of the connotation derived from alarm as it represents activity, enthusiasm, punctuality and getting back to life. Hence, it can be said that Nescafé is as necessary to your day as your alarm clock to wake you up. In this advertisement, the metaphorical meaning of the image is linguistically supported by the text. It is the text that reveals the name of the product therefore it directs the perception of the visual metaphor. Furthermore, the anchoring imperative 'wake up to live' suggests that Nescafe is the first step you should take to get to this destination. The visual metaphor alone is not enough to construe the intended meaning as the text and

(Analysis of Visual and Verbal Rhetorical Strategies...) Reham Sayed 


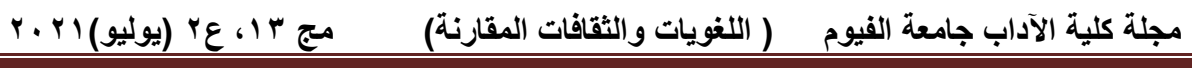

the product's name help cue the source domain. In the verbo-pictorial structure, the image and the text combine to trigger a metaphor.

\section{Ad No.3}

1) Product name: McDonald's

- Type of product: Sandwich

- Text inside the image: Free Wi-Fi served at all restaurants

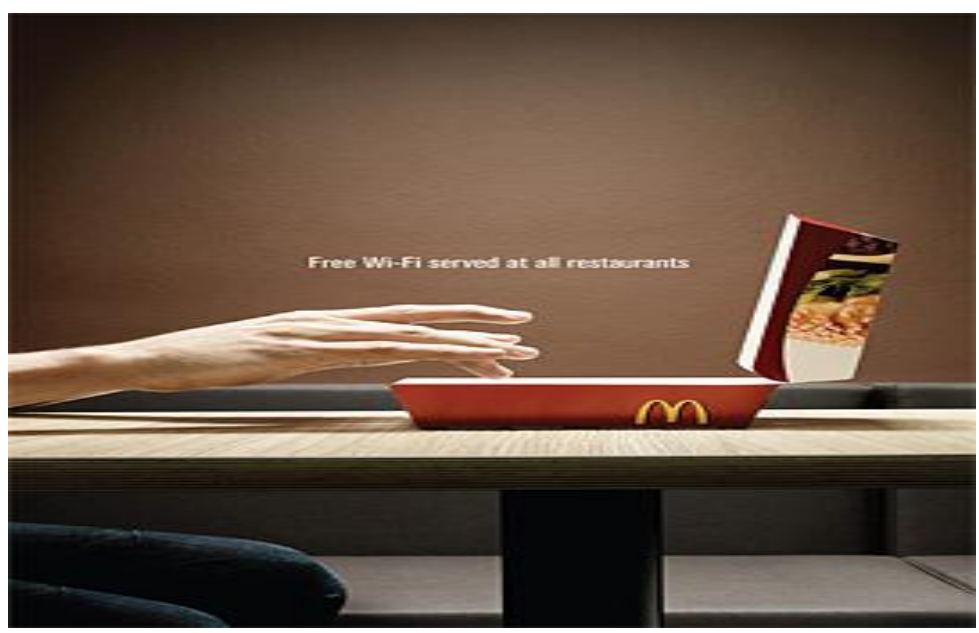

Figure (6)

This advertisement shows a McDonald's burger shaped like a laptop in order to achieve the message for its audience that you can still enjoy the food and use your time wisely through the free $\mathrm{Wi}-\mathrm{Fi}$ provided there. The producer

(Analysis of Visual and Verbal Rhetorical Strategies...) Reham Sayed 
uses verbal and non-verbal elements in this advertisement to clearly deliver his message to readers. The similarity between the Laptop and McDonald's burger box is created via the opened up hamburger box represent a laptop and the hands of a man in the typing position with the wording, "Free Wi-Fi served at all restaurants". We can infer from the text and the image that the promotable attribute is that this restaurant is now appealing to busy workers who are in needed of a meal yet they are under a tight schedule that they cannot leave their laptops at home.

In the verbo-pictorial metaphor, the text acts as the linguistic support of the image. From the (barely readable) tag line 'Free Wi-Fi served at all restaurants', we can deduce that the Wi-Fi service, rather than for instance the meal's price or its taste is the attribute to be promoted in this ad. The text therefore enhances a product feature, thus working as an advertising strategy. The text 'Free Wi-Fi served at all restaurants' has two functions: (1) it supports the visual metaphor by explaining why the restaurant is the best choice for the consumer who frequently uses technological devices; and (2) it illustrates a pragmatic

(Analysis of Visual and Verbal Rhetorical Strategies...) Reham Sayed 
function of metaphor. Thus, we can deduce that the function of the text is to 'fix' visual meaning.

\section{Results of Variance Analysis (Quantitative Analysis)}

In order to analyze the effect of verbal and pictorial metaphors within advertisements on the participants' comprehension and attitude toward the ad, the participants' answers must be evaluated at first. This evaluation is conducted by using the statistical program SPSS. The experiment was implemented with the univariate analysis of variance (ANOVA) to examine the effect of different types of pictorial metaphors on the attitude toward the ad and comprehension of the ad message.

A repeated measure factorial ANOVA was performed on the calculated differences between the two appearances of visual metaphor in order to test their effect on ad subjective comprehension. The hypotheses claimed that ad subjective comprehension will increase gradually starting from replacement, moving through verbo-pictorial structures. In light of the following table of Mean and Standard Deviations, results from ANOVAs (analysis of

(Analysis of Visual and Verbal Rhetorical Strategies...) Reham Sayed 
variance) indeed showed that there was a significant difference between verbo-pictorial $(\mathrm{M}=2.60, \mathrm{SD}=0.62)$ and replacement $(\mathrm{M}=2.72, \mathrm{SD}=0.52), \mathrm{p}<.05$. This means that advertisements employed verbo-pictorial metaphor $(\mathrm{M}=$ 2.60, $\mathrm{SD}=0.62$ ) was comprehended less than advertisements with replacement metaphor $(\mathrm{M}=2.72, \mathrm{SD}=0.52), \mathrm{p}<.05$. Put in another way, visual metaphor ads with replacement structure were comprehended better than ads with verbopictorial structure. This is contrary to our prediction in hypothesis (1).

Based on visual structure, hypothesis (3) was partially accepted. As per the results, replacement structure elicited greater ad liking compared to verbo-pictorial structures. The following graphs presents the results of univariate test for the ad likeability ratings. Note that the significance value applied in this test was .01 and it can be seen that all variables were below .01 significance values. Therefore, it can be said that visual metaphor type affects the consumer's attitude toward the ad. The findings of the current study are consistent with these discussions in academia. With regard to attitude toward the ad results from ANOVA showed that there was a significant effect for the visual metaphor type on

(Analysis of Visual and Verbal Rhetorical Strategies...) Reham Sayed 
ad likeability. The noticeable difference was between the verbo-pictorial structure $(\mathrm{M}=3.4, \mathrm{SD}=1.3)$ and replacement $(\mathrm{M}=2.72, \mathrm{SD}=0.52)$. Hence, hypothesis (3) was partially accepted. According to the results, replacement structure elicited greater ad liking compared to verbo-pictorial structures.

Table1. Mean and Standard Deviations Associated with Dependent Variables ( $=90)$.

\begin{tabular}{|l|c|c|c|c|}
\hline $\begin{array}{l}\text { Dependent } \\
\text { Variables }\end{array}$ & \multicolumn{2}{|c|}{$\begin{array}{r}\text { Verbo-pictorial } \\
\text { Metaphor }\end{array}$} & \multicolumn{2}{|c|}{$\begin{array}{r}\text { Replacement } \\
\text { Metaphor }\end{array}$} \\
& Mean & Seviation & Mean & $\begin{array}{r}\text { Std. } \\
\text { Deviation }\end{array}$ \\
\hline $\begin{array}{l}\text { Subjective } \\
\text { Comprehension }\end{array}$ & 2.6056 & 0.62032 & 2.7222 & 0.52037 \\
$\begin{array}{l}\text { Objective } \\
\text { Comprehension } \\
\text { Attitude toward } \\
\text { the ad. }\end{array}$ & 3.4444 & 1.39376 & 3.9074 & 1.02043 \\
\hline
\end{tabular}

(Analysis of Visual and Verbal Rhetorical Strategies...) Reham Sayed 
The bar graphs below represent an additional visual illustration for the data shown in the table above in order to help the reader to better conceive the statistics and eventually receive the intended message from the result analysis.

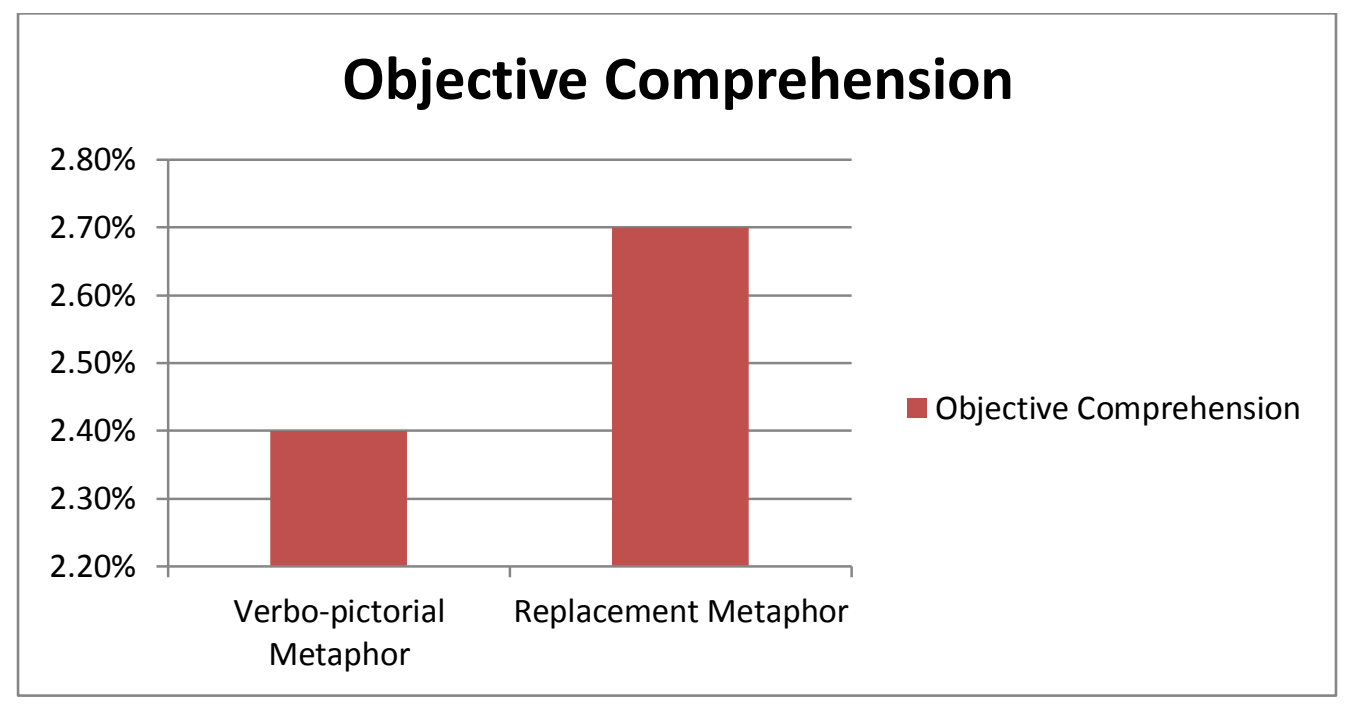

Figure 1: ANOVAs analysis of objective comprehension.

(Analysis of Visual and Verbal Rhetorical Strategies...) Reham Sayed 


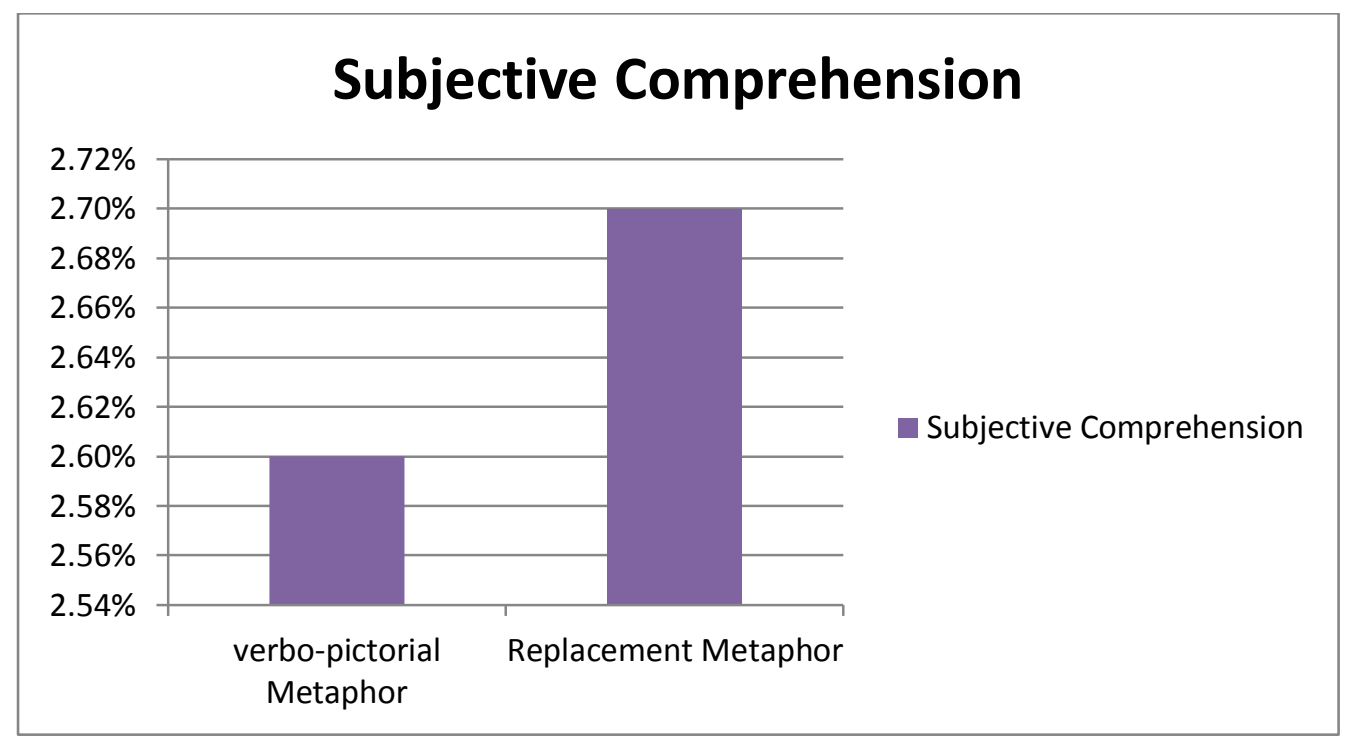

Figure2: ANOVAs analysis of objective comprehension.

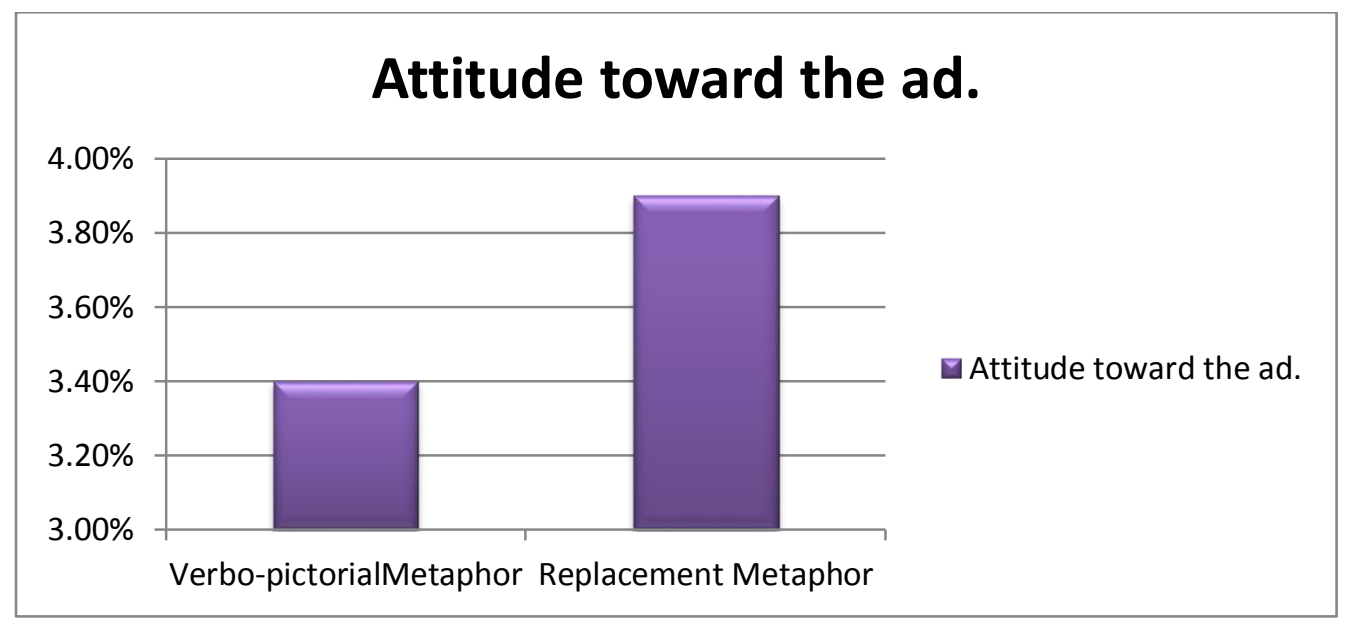

Figure3: ANOVAs analysis of attitude toward the ad.

(Analysis of Visual and Verbal Rhetorical Strategies...) Reham Sayed 


\section{Discussion}

Unlike the previous academic findings that reveal that the ads consisting of more complex dimensions (replacement) cause more difficulty for the readers or viewers to comprehend, the current research results related to the objective metaphor comprehension are not connected to the findings, yet their explanation is very significant as advert comprehension is an important component of the overall ad effectiveness. One more disagreement with previous academia this field was that participants indicated that the most comprehensible ads were the ones with replacement visual structures, they also found advertisements with verbo-pictorial metaphors least comprehensible. In the case of replacement structure depends mainly on absence thus the comparison between two objects where one of the terms is missing represents a challenge for the viewer comprehension skills.

It is worth noting that the above-mentioned result provides evidence that participants focus on the common functional characteristics between the compared domains when solving the metaphorical adverts. For instance, with the objective metaphor comprehension questions, the

(Analysis of Visual and Verbal Rhetorical Strategies...) Reham Sayed 
participants were asked to choose one single characteristic that the two metaphorical objects (concepts) have in common. The analysis of their answers reveals that the viewers' perception of contextual inappropriateness or conceptual similarity refers to the way the elements are similar in their function (and not necessary in their appearance or material). In a nut shell, the present study attempted to prove that visual metaphor type effects consumer response which was accomplished.

Verbo-pictorial type of metaphor ad was found to be less effective and this is contradicting with the current experiment predictions. Overall view, significant differences were found between verbo-pictorial metaphor and replacement metaphor. With the mediating and final response in mind, such type of multimodal visual metaphor scored the lowest among the other types of metaphor. Similarly, the mediation effect of subjective ad comprehension and objective ad comprehension tended to lean more towards a negative direction.

Unlike the replacement metaphor, Forceville's multimodal metaphor (verbo-pictorial) depends on a comparison between a visual (usually represents the product

(Analysis of Visual and Verbal Rhetorical Strategies...) Reham Sayed 
image) and a verbal object. The existence of verbal anchoring sometimes creates negative effects and elicits unintended consumer response to the ad. The verbal copy facilities comprehending the ad image and at the same time it decreases the amount of cognitive elaboration required to solve the metaphorical incongruity. Given that the viewer is supposed to enjoy handling the ad puzzle, the full explanation of the riddle negatively affects the pleasure evoked by the trope and may lead to negative attitude toward the ad. In harmony with that, many previous studies provide possible explanation for the negative result related to the verbo-pictorial metaphor and research proposes that implicit visual argument may provide a more persuasive effect than explicit visual argument which is anchored by verbal explanation (Phillips 2000, Jeong 2008).

An opposing result was suggested by Van Enschot et al. (2015) and Philips (2000) who stressed the role the text anchoring plays in increasing the viewer's comprehension. They propsed that the more explanatory information was given, the higher the comprehension of the advert would be. However, this is clearly contradicting with the previously mentioned findings of the current study.

(Analysis of Visual and Verbal Rhetorical Strategies...) Reham Sayed 


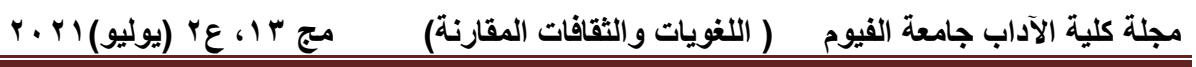

\section{Conclusion}

It was then clear that pictorial metaphor is a highly influential tool that advertisers can easily utilize in advertising design to influence consumers and make the advertisement aesthetically and cognitively appealing because visual metaphors was found the most comprehended or liked by consumers.

(Analysis of Visual and Verbal Rhetorical Strategies...) Reham Sayed 


\section{References}

Forceville, C. (1994). Pictorial metaphor in advertisements. Metaphor and Symbolic Activity, 9, pp.1-29.

Forceville, C. (1996). Pictorial Metaphor in Advertising. London: Routledge.

Gkiouzepas, L., \& Hogg, M. K. (2011). Articulating a New Framework for Visual Metaphors in Advertising, Journal of Advertising, 40(1), pp.103-120.

Goddard, A. (2002). The Language of Advertising: Written Texts $\left(2^{\text {nd }}\right.$ ed. $)$, Routledge: Intertext Series.

Hermerén, L. (1999), English for sale: A study of the language of advertising. Lund Studies in English: Lund University Press

Jeong, S. H. (2008). Visual Metaphor in Advertising: Is the Persuasive Effect Attributable to Visual Argumentation or Metaphorical Rhetoric?, Journal of Marketing Communications, 14(1), pp.59-73.

Kress, G., \& Leeuwen, T. (2006). Reading images: The grammar of visual design. London: Routledge.

(Analysis of Visual and Verbal Rhetorical Strategies...) Reham Sayed 
Lutz, R. J. (1985). Affective and cognitive antecedents of attitude toward the ad: A conceptual framework. Psychological processes and advertising effects, pp. 45-63.

Ma, L. (2008). Pictorial Metaphor in Advertising and Consumer Interpretation of its Cultural Meaning. China Media Research, 4(3), pp. 9-17.

McQuarrie, E. F., \& Mick, D. G. (1996). Figures of Rhetoric in Advertising Language. Journal of Consumer Research, 22, pp.424-438.

McQuarrie, E. F., \& Mick, D. G. (1999). Visual rhetoric in advertising: Text-interpretive, experimental, and readerresponse analyses. Journal of Consumer Research, 26(1), pp.37-54.

Mick, D. G. (1992). Levels of subjective comprehension in advertising processing and their relations to ad perceptions, attitudes, and memory. Journal of Consumer Research, pp.411-424.

Morgan, S. E., \& Reichert, T. (1999). The message is in the metaphor: Assessing the comprehension of metaphors in advertisements. Journal of Advertising, 28(4), pp.1-12.

(Analysis of Visual and Verbal Rhetorical Strategies...) Reham Sayed 
Phillips, B. (1997). Thinking into it: Consumer Interpretation of Complex Advertising Images. Journal of Advertising, pp.7787.

Phillips, B. J. \& McQuarrie, E. (2004). Beyond visual metaphor: A new typology of visual rhetoric in advertising. Marketing Theory, 4, pp.113-136.

Phillips, B. J. (2000). The impact of verbal anchoring on consumer response to image ads. Journal of Advertising, 29 (1), pp.15-25

Schilperoord, J. (2016). Ways with Pictures: Visual incongruities and metaphor. Manuscript to appear. Tilburg University.

Thorson, E. (1990). Consumer Processing of Advertising. In : Janis H. Leigh and Claude Martin, Jr., (Eds.), Current Issues and Research in Advertising, , Ann Arbor, MI: University of Michigan School of Business, pp.197-230

Van Enschot, R., \& Hoeken, H. (2015). The occurrence and effects of verbal and visual anchoring of tropes on the perceived comprehensibility and liking of TV commercials. Journal of Advertising 24(1), pp. 25-36.

(Analysis of Visual and Verbal Rhetorical Strategies...) Reham Sayed 
Van Enschot, R., \& Van Hooijdonk, C. (2016). The pleasure of processing visual metaphor in advertising. International Journal of Marketing \& Business Communication, 5(4), pp.1-14

Van Mulken, M., le Pair, R., \& Forceville, C. (2010). The impact of perceived complexity, deviation and comprehension on the appreciation of visual metaphor in advertising across three European countries. Journal of Pragmatics, 42(12), pp.3418-3430.

Van Mulken, M., Van Hooft, A., \& Nederstigt, U. (2014). Finding the Tipping Point: Visual Metaphor and Conceptual Complexity in Advertising. Journal of Advertising, 43(4), pp.333-343.

(Analysis of Visual and Verbal Rhetorical Strategies...) Reham Sayed 


\section{تحليل لغوي معرفيـ}

للاستراتيحيات البلاغية البصرية واللفظية في الخطاب الإعلاني

\section{ملخص - ملن}

الاستعارة التصويرية هي شكل من أشكال اللغة الخطابية التي ينم تجسيدها

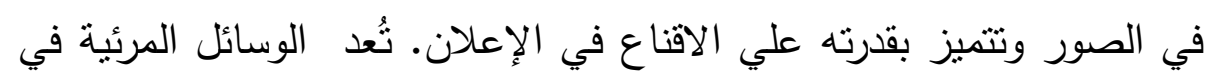

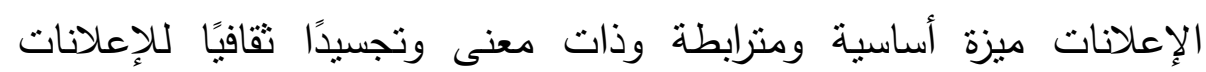

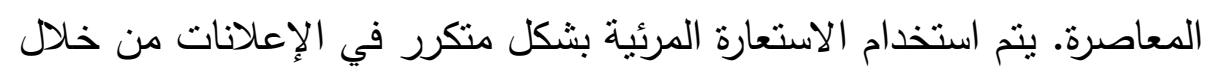

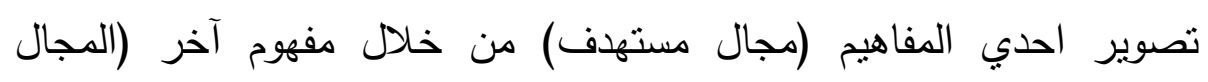
المصدر). ولقد اهتم البحث الأكاديمي في بادئ الأمر بدراسه المجاز اللفظي، تحول التركيز البحثي من الاستعارة اللفظية إلى المجاز المرئي. يهدف البحث الحالي إلى قياس تأثير نوعين مختلفين من الاستعارات علي مدي استجابه المستهلك للاعلان وهما: الاستعارة المرئيه اللفظيه والاستعاره البديله. شارك في هذه التجربة مجموعة من ، م أستاذًا من ثلاث جامعات مصرية. تم قياس مواقفهم تجاه الاعلانات المختاره ومدي ادراكهم للمجاز المرئي. اعتمد البحث ف تحليل النتائج علي نظريه فيليبس وماكوري ناهي

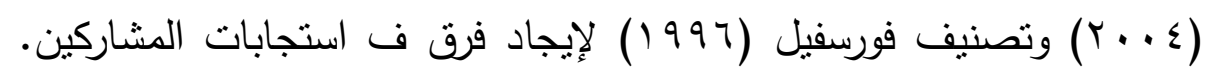
تشير النتائج المتعلقة بفهم الاستعارة الموضوعي إلى أهمية الخصائص الوظيفية كعنصر رئيسي يركز عليه المشاركون عند فهم الاستعارات المرئية.

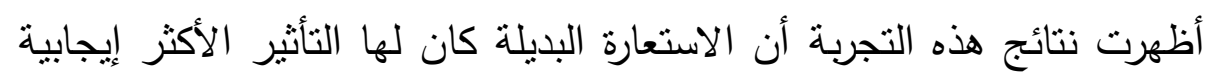
على فهم المتلقي للإعلانات المختارة. الكلمات المفتاحية: الاستعارة اللفظية- الاستعارة البصرية - فورسفيل

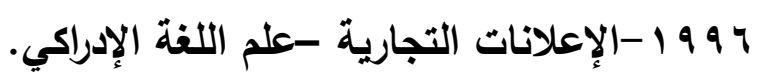

(Analysis of Visual and Verbal Rhetorical Strategies...) Reham Sayed 